\title{
Follicle and oocyte growth in early postnatal calves: cytochemical, autoradiographical and electron microscopical studies
}

\author{
AJ Mhawi, J Kaňka, J Motlík \\ The Czechoslovak Academy of Sciences, Institute of Animal Physiology and Genetics, \\ Department of Genetics, 27721 Libə̌chov, Czechoslovakia.
}

(4th Franco-Czechoslovak Meeting, Prague 1990)

\begin{abstract}
Summary - The initiation of oocyte and follicle growth was studied in 1- and 3-d-old calf ovaries using cytochemical, autoradiographical and electron microscopical approaches. Attention was only paid to unilaminar ovarian follicles that were classified into 3 categories: unilaminar flattened (UF), unilaminar flatto-cuboidal (UFC) and unilaminar cuboidal (UC) ovarian follicles when the oocyte was surrounded by 1 layer of flattened, a mixture of flattened and cuboidal and entirely cuboidal follicle cells, respectively. Our findings suggested that oocytes within each of these follicle categories were in different developmental stages. Furthermore, electron microscopic observations revealed that early after birth, oocyte nuclei characteristic of diplotene configuration (aggregation of the nuclear chromatin into moderately electron-dense small patches and fibrillo-granular texture of the nucleolus) were encountered in $41 \%$ of the UF follicles. The rest of the UF as well as all of the UFC and UC follicles were found to contain dictyate oocytes in which the chromatin was highly decondensed and the nucleolus differentiated into fibrillar, fibrillo-granular and granular components. The present results also indicated that the complete transition of the surrounding follicle cells from flattened to cuboidal shape and the morphological changes of the oocyte endoplasmic reticulum and mitochondria were 2 complementary events essential for initiation of oocyte growth.
\end{abstract}

oocyte / follicle / bovine / early postnatal period

Résumé - Crolssance folliculaire et ovocytaire chez les veaux nouveau-nés : études cytochimiques, autoradlographiques et ultrastructurales. Le début de la croissance ovocytaire et folliculaire a été étudié dans des ovaires de veaux de 1 et $3 j$ à l'aide de techniques cytochimiques, autoradiographiques et ultrastructurales. Notre attention s'est portée seulement sur les follicules unilaminaires classés en 3 catégories : follicules à paroi unilaminaire de cellules squameuses (UF) ou squamo-cuboidales (UFC) ou cuboïdales (UC). Nos résultats indiquent que les ovocytes de chacune de ces catégories sont à des stages de développement différents. En outre, les observations au microscope électronique ont montré que les noyaux au stade diplotène (chromatine agrégée en mottes modérément opaques, nucléole à texture fibrillo-granulaire) se trouvent dans $41 \%$ des follicules de la catégorie UF. Les autres follicules de type UF ainsi que les follicules des types UFC et UC contiennent des ovocytes au stade dictyé (chromatine très condensée, nucléole différencié en composants fibrillaires, fibrillo-granulaires et granulaires). Enfin la transition de la forme squameuse à la forme cuboidale des cellules de la paroi folliculaire et le changement du reticulum endoplasmique et de mitochondries apparaissent contemporains du démarrage de la croissance ovocytaire.

ovocyte / follicule / bovin / période post-natale

" Correspondence and reprints 


\section{INTRODUCTION}

Follicle growth has been proposed to involve the passage of follicle from a dormant to growth phase, through a transitory stage (Cahill and Mauléon, 1981). However, during the dormant phase, the follicle cells undergo a progressive transformation from a flattened to a cuboidal shape (Gougeon and Chainy, 1987).

The essential role of follicle cells in oocyte growth initiation was mainly documented in rodents. In the mouse, oocytes have been suggested to grow when they become predominantly surrounded by $\mathrm{cu}$ boidal follicle cells (Lintern-Moore and Moore, 1979a). The progressive accumulation and transformation of follicle cells from a flattened to a cuboidal shape stimulates the oocyte nucleolar RNA synthesis, the first event in the initiation of oocyte growth (Lintern-Moore and Moore, 1979b). Furthermore, Buccione et al (1987) have concluded that follicle cells, besides the nutrients, provide the growing oocyte with a specific factors(s) required for its growth.

Despite the intensive efforts which were devoted to studying the process of folliculogenesis in cycling heifers and cows (Rajakoski, 1960; Matton et al, 1981; Maurasse et al, 1985; Savio et al, 1988), no data are available concerning follicle and oocyte growth initiation in early postnatal calves. In the present study, cytochemical and autoradiographical data were correlated with electron microscopical observations in an effort to investigate the initiation of follicle and oocyte growth in early postnatal calves.

\section{MATERIAL AND METHODS}

One- and 3-d-old calf ovaries of the Czech redspotted breed were obtained by midventral laparotomy and immediately subjected to cytochemical, autoradiographical and electron microscopical experimental approaches.
In all experiments, attention was paid only to unilaminar ovarian follicles that were classified into 3 categories: unilaminar flattened (UF), unilaminar flatto-cuboidal (UFC) and unilaminar cuboidal (UC) ovarian follicles when the oocyte was surrounded by 1 layer of flattened, a mixture of flattened and cuboidal and by entirely cuboidal follicle cells, respectively. No differences in the follicle parameters were found between the two studied intervals and, therefore, data were pooled. The number of scored follicles examined in cytochemical and autoradiographical experimental approaches is indicated in figures 1 and 3, respectively. For electron microscopy, the number of examined follicles is indicated in the respective legends.

\section{Cytochemistry}

The ovarian cortex was cut into small pieces $(0.5-2 \mathrm{~mm})$ and fixed either in Zenker's solution for $24 \mathrm{~h}$ at $4{ }^{\circ} \mathrm{C}$ or in Carnoy solution for $3 \mathrm{~h}$ at $4^{\circ} \mathrm{C}$ and prepared for histological examination. Five- $\mu \mathrm{m}$ thick serial sections were cut, mounted on microscopic slides and stained with Feulgen reaction for nuclear DNA visualization (Gurr, 1962). Carnoy-fixed tissues were pretreated with ribonuclease (RNase) to serve as a control of the specificity of the Feulgen reaction. The RNase used (pyrimidine 2'-D-ribonucleotide transferase) was isolated from the bull seminal vesicle (Dostál and Matoušek, 1973) and the enzyme reaction was carried out according to Lillie (1965). Feulgen reaction of the oocyte nuclei was divided arbitrarily into 4 classes with regard to the degree of the staining reactions: intensive, moderate, weak and negative Feulgen reaction. The number of follicle cells per crosssection, oocyte diameter and follicle diameter were obtained only from sections in which the oocyte nucleolus was visible. These sections were considered as the largest cross-sections. The follicle and oocyte diameters were estimated as a mean of 2 measurements taken at right angles.

\section{Autoradiography}

Sheets of the ovarian cortex $(0.2-0.5 \mathrm{~mm})$ were cut and incubated at $37{ }^{\circ} \mathrm{C}$ for $1 \mathrm{~h}$, in tissue culture medium (Crozet et al, 1981) en- 
riched with 5-3 $\mathrm{H}$-uridine (UVVVR, Prague, specific activity $765 \mathrm{GBq} / \mathrm{mol}$ ) to a final concentration of $7.4 \mathrm{MBq} / \mathrm{ml}(200 \mu \mathrm{Ci} / \mathrm{ml})$. After incubation, the tissues were thoroughly washed in cold $\left(+4^{\circ} \mathrm{C}\right)$ phosphate buffer solution and used either for paraffin or Epon embedding.

For paraffin embedding, tissues were fixed for $6 \mathrm{~h}$ in $4 \%$ paraformaldehyde in $0.3 \mathrm{M}$ phosphate buffer (pH 7.2) at $4{ }^{\circ} \mathrm{C}$, washed for $5 \mathrm{~h}$ in phosphate buffer, dehydrated and embedded in paraffin. Approximately 5- $\mu \mathrm{m}$ thick serial sections were cut and mounted on microscope slides.

Tissues designed for Epon embedding were fixed for $4.5 \mathrm{~h}$ in $4 \%$ paraformaldehyde in $0.3 \mathrm{ca}$ codylate buffer $(\mathrm{pH} 7.3)$ at $4^{\circ} \mathrm{C}$. After washing for $20 \mathrm{~min}$ in the same buffer, the tissues were postfixed for $1.5 \mathrm{~h}$ in $1 \% \mathrm{OsO}_{4}$, dehydrated and embedded in Epon 812. Serial semi-thin $(0.5$ $\mu \mathrm{m})$ sections were cut and mounted on microscope slides. Paraffin- and Epon-embedded sections were coated with nuclear liquid emulsion (IIford K5) and exposed at $4{ }^{\circ} \mathrm{C}$ for either 7 $d$ (paraffin-embedded sections) or $9 \mathrm{~d}$ (Eponembedded sections). After development with solution D $19 \mathrm{~b}$ (Kodak) and fixation, the autoradiograms were stained with either hematoxylin and eosin (paraffin sections) or with methylene blue (Epon sections). After subtraction of the number of silver grains which appeared in the unit area of the background, labelling intensity of the oocyte nuclei was arbitrarily classified into 4 groups: very intensive, intensive, moderate and weak when $\geq 30,20-29,10-19$ and 1-9 silver grains were counted on the oocyte nuclear area, respectively. The number of follicle cells per largest cross-section, oocyte diameter and follicle diameter were only estimated from sections in which both follicle cells and oocyte nuclei were labelled and in which the oocyte nucleolus had appeared.

\section{Electron microscopy}

Small pieces of the ovarian cortex were fixed immediately for $2-5 \mathrm{~h}$ in $2.5 \%$ glutaraldehyde and $0.6 \%$ paraformaldehyde in $0.3 \mathrm{M}$ cacodylate buffer $/ \mathrm{pH} 7.2 /$ at $4^{\circ} \mathrm{C}$. After washing in this buffer, they were postfixed for $1.5 \mathrm{~h}$ in $\mathrm{OsO}_{4}$, dehydrated with alcohol and embedded in Epon 812. Thin sections were stained with uranyl acetate for $20 \mathrm{~min}$ and sodium citrate for $5 \mathrm{~min}$.

\section{Statistical analysis}

Data were analysed using Student's t-test. A probability of $<0.05$ was considered statistically significant.

\section{RESULTS}

\section{Cytochemistry}

In each follicle category, the oocyte nucleus, whether pretreated with RNase or not, exhibited 4 classes of Feulgen reaction: intensive, moderate, weak and negative. Nuclei of the surrounding follicle cells were always Feulgen intensive. In each follicle category, while the oocyte Feulgen intensity decreased, the number of follicle cells per largest cross-section and the follicle diameter increased concomitantly. The increase in these follicle parameters was paralleled with a non-significant increase in oocyte diameter (fig 1). However, a significant increase $(P<0.05)$ in oocyte diameter was only observed in the Feulgen negative class of the UC follicles when compared with the same Feulgen class of the UF follicles.

Abnormally grown $(34.6 \pm 3.93 \mu \mathrm{m}$ in diameter), Feulgen negative, oocytes which were invested with only one layer of flattened follicle cells and referred to as "giant oocytes" were observed frequently (figs $2 \mathrm{~d}$ and 9). The frequency of these oocytes in the examined ovarian sections increased with animal age.

\section{Autoradiography}

Each follicle category exhibited 4 groups of oocyte labelling intensity: weak, moderate, intensive and very intensive (fig 2). In each follicle category, concomitant with the in- 

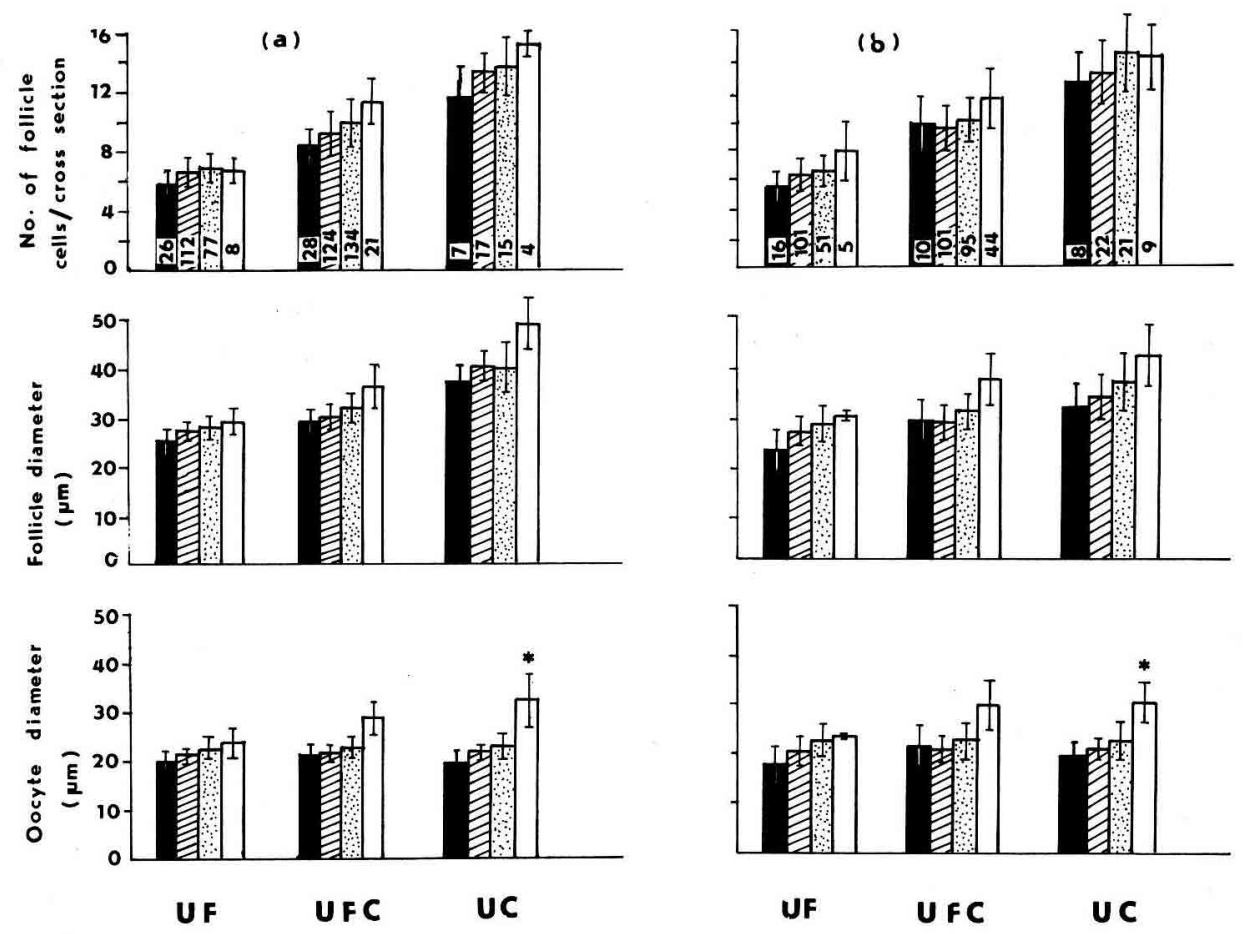

Fig 1. Number of follicle cells per largest cross section, follicle diameter and oocyte diameter in the in-

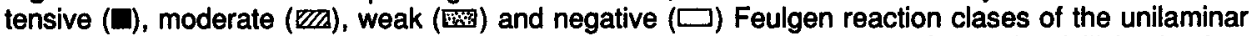
flattened /UF/, unilaminar flatto-cuboidal (UFC) and unilaminar cuboidal (UC) ovarian follicles in a) 1. $d$-old and b) 3-d-old calves. The number of scored follicles is shown by figures in upper columns. * $P<0.05$ when compared with the group of the Feulgen negative oocytes of the UF follicles.

crease in oocyte labelling intensity, follicle cell number per largest cross-section as well as follicle diameter was increased. The increase in these follicle parameters was paralleled with a non-significant increase in oocyte diameter (fig 3). Oocyte diameter only increased significantly $(P<$ 0.05 ) in the very intensive labelling group of the UC follicles when compared with the same labelling intensity group of the UF follicles. The "giant oocytes" exhibited either intensive or very intensive labelling.

\section{Electron microscopy}

In each follicle category, electron microscopy revealed 2 different populations of oocytes. In the UF follicles, the 2 oocyte populations were different from each other in nuclear configuration and cytoplasmic development. In the first population (41\%), the oocyte nuclear chromatin aggregated into moderately electron-dense small patches (fig 4). The nucleoli were mainly fibrillo-granular in texture within which small 

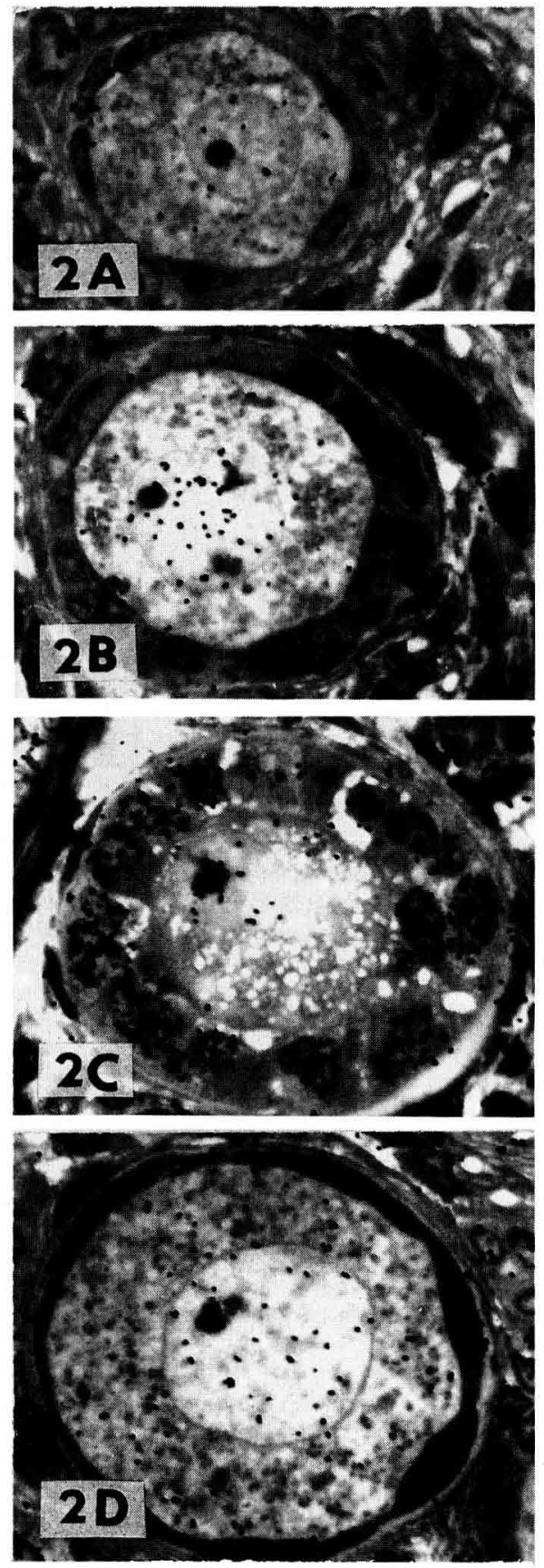

fibrillar areas could be recognized. A small number of non-differentiated mitochondria as well as small vesicular elements of endoplasmic reticulum were found in the cytoplasm (fig 4). Nuclei of the second oocyte population of the UF follicles possessed a uniformly decondensed chromatin (fig 5). The nucleoli were reticulated and differentiated into fibrillar, fibrillogranular and granular components. In the cytoplasm, an abundance of welldifferentiated mitochondria associated with flattened cisternae of endoplasmic reticulum could be seen (fig 5).

As the follicles grew from UF to UFC or UC stages, the 2 oocyte populations of each follicle category became similar in nuclear configuration: both oocyte populations exhibited a uniformly decondensed nuclear chromatin (figs 6,7 and 8) and contained nucleoli which were differentiated into fibrillar, fibrillo-granular and granular components assuming a reticulated form. Cytoplasmic examination indicated that the oocyte population of the UFC or that of the UC follicles were alike in the distribution of numerous well-differentiated mitochondria and differed mainly in the development of endoplasmic reticulum (figs 6 and 7). While it appeared as scarcely visible vesicular elements in the first population (fig 6), the endoplasmic reticulum was recognized as well-differentiated flattened cisternae in the second population (fig 7).

Fig 2. Representative photographs of A) unilaminar flattened (UF), B) unilaminar flattocuboidal (UFC), C) unilaminar cuboidal (UC) ovarian follicles and D) a "giant oocyte" invested in one layer of flattened follicle cells. The incorporation of the labelled RNA precursor into the nuclei of these particular oocytes is weak (A), moderate (C) and intensive (B, D). 

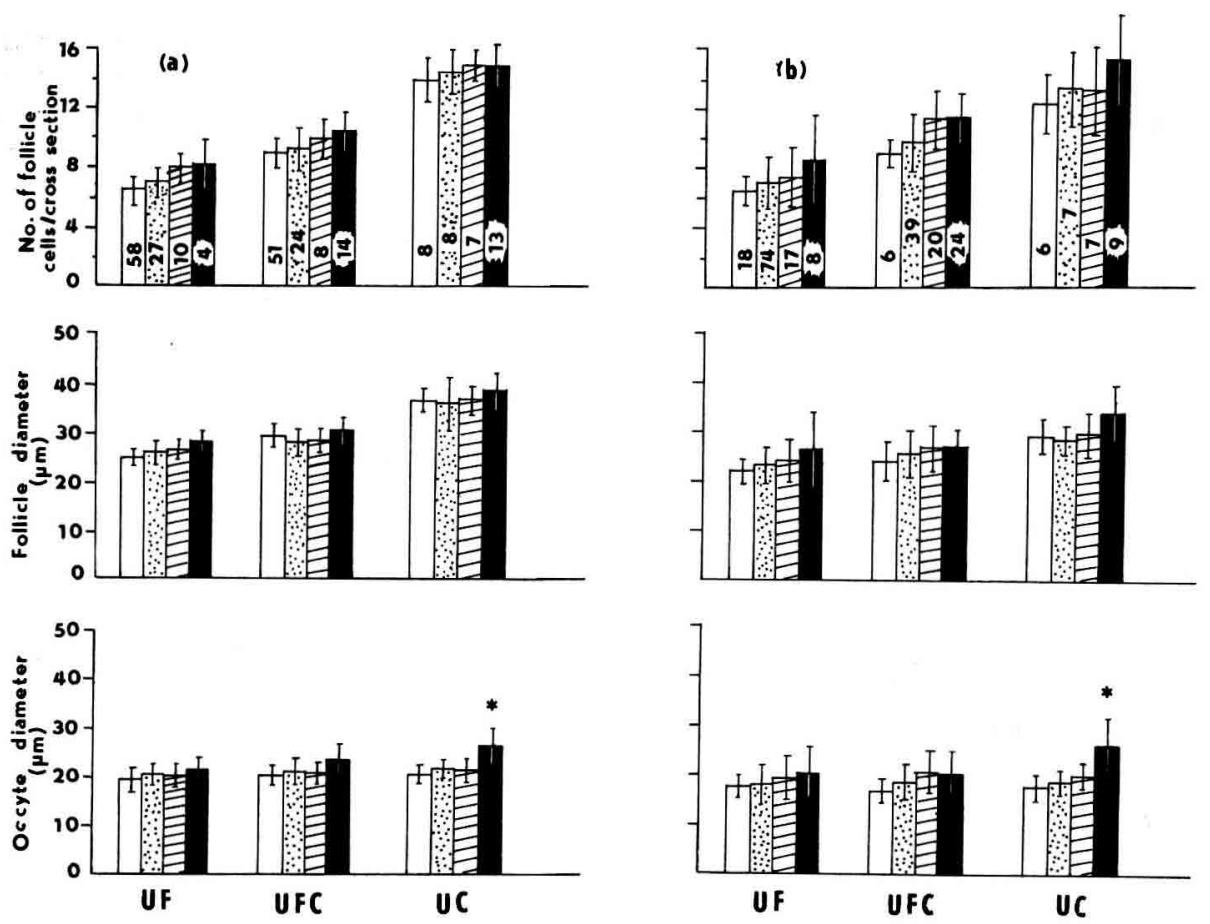

Fig 3. Number of follicle cells per largest cross section, follicle diameter and oocyte diameter in the

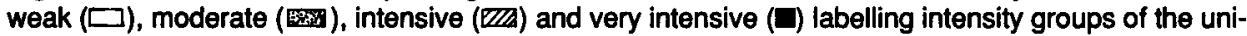
laminar flattened /UF/, unilaminar flatto-cuboidal /UFC/ and unilaminar cuboidal /UC/ ovarian follicles of a) 1-d-old and b) 3-d-old calves. The number of scored follicles is shown by figures in upper columns. $P<0.05$ when compared with the very intensive labelling group of the UF follicles.

Fig 4. An electron micrograph of a unilaminar flattened ovarian follicle (UF) with an oocyte of population $1(n=5)$. The oocyte nuclear chromatin aggregates into moderately electron-dense small patches (arrowhead). The nucleolus (inset, $x 10000$ ) is mainly fibrillo-granular in texture within which small fibrillar areas can be recognized (arrow). Scarce non-differentiated mitochondria $(\mathrm{m})$ and small vesicular elements of the endoplasmic reticulum (ver) are visible in the cytoplasm (x 1500$)$.

Fig 5. An electron micrograph of a unilaminar flattened ovarian follicle (UF) with an oocyte of population $2(n=7)$. The oocyte nuclear chromatin decondenses uniformly. The larger reticulated nucleolus (inset, $\times 8000$ ) differentiates into fibrillar, fibrillo-granular and granular components. Abundance of well-differentiated mitochondria $(\mathrm{m})$ associated with flattened cisternae of endoplasmic reticulum (fer) are seen in the cytoplasm $(\times 1500)$. 


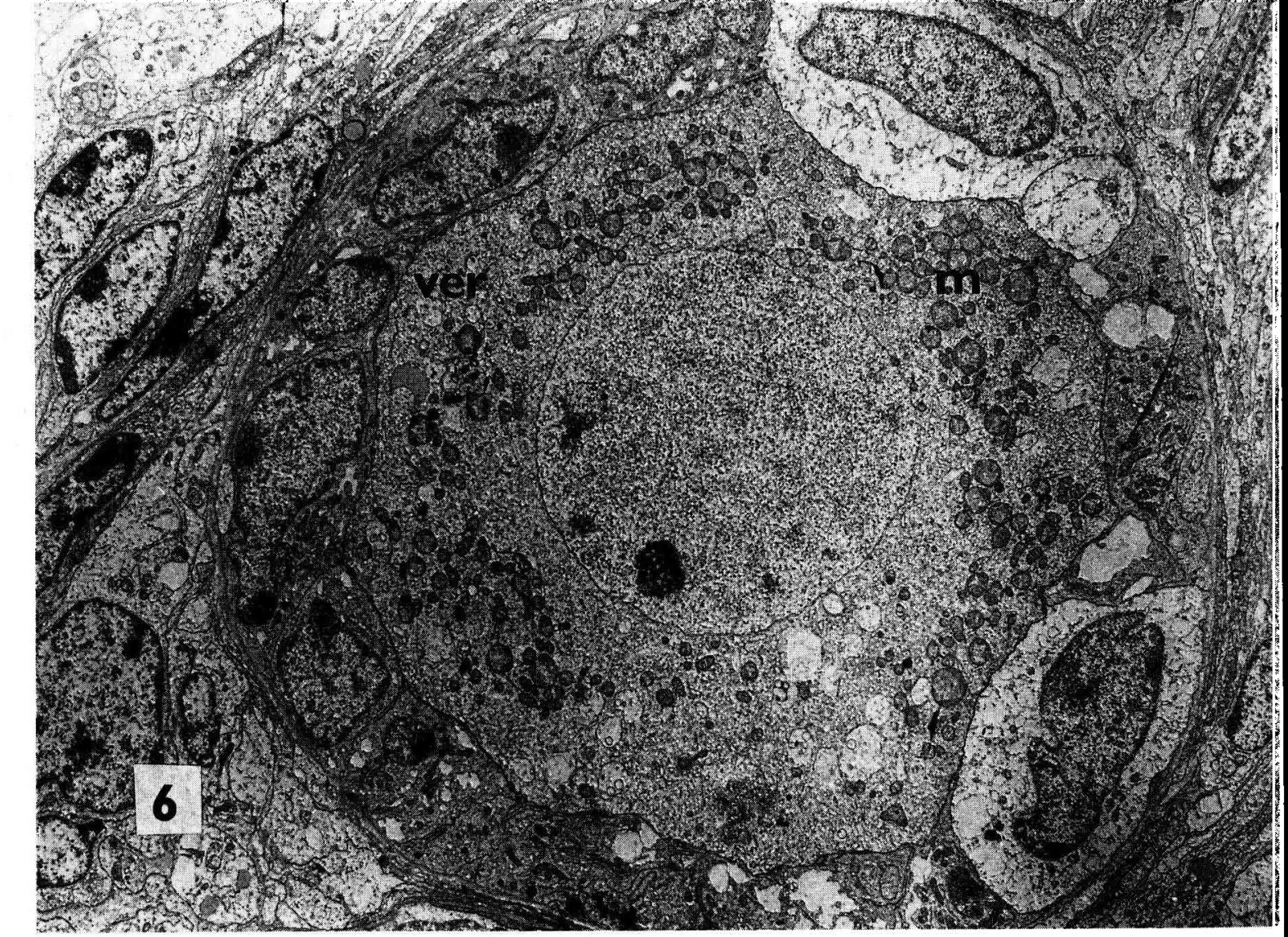

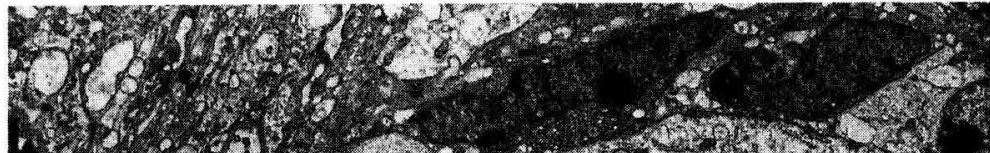

.

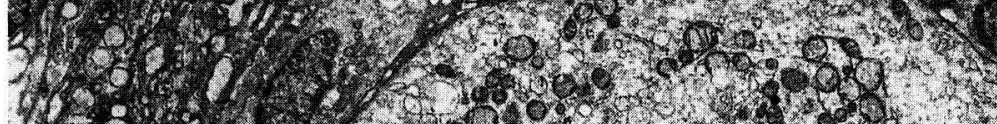

(5)

20.

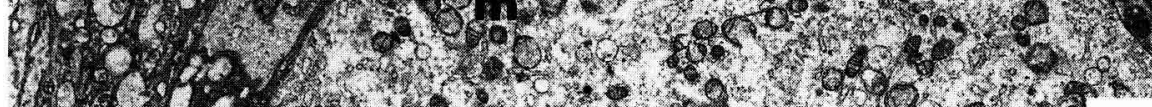

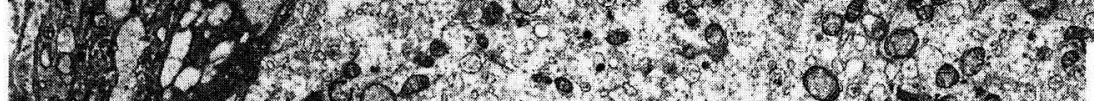

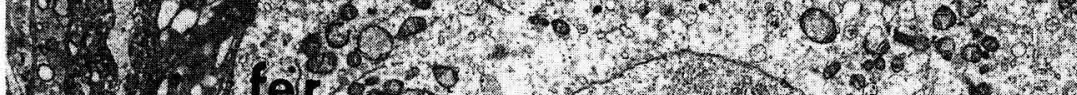

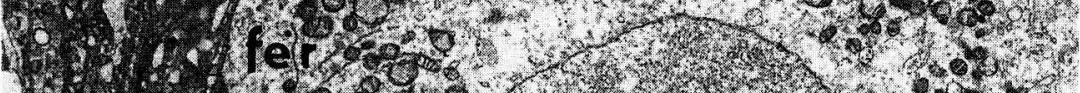

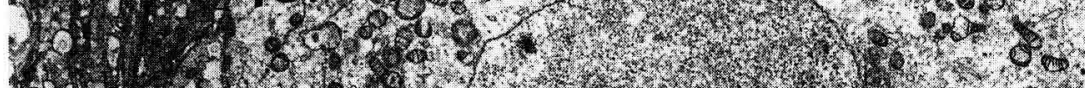

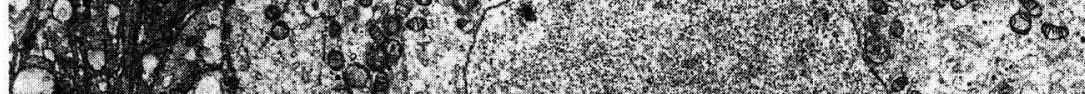

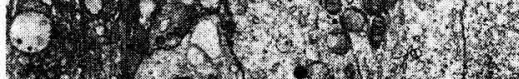

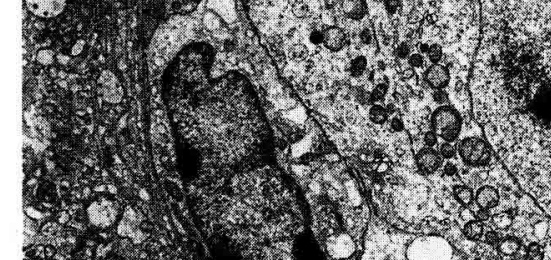

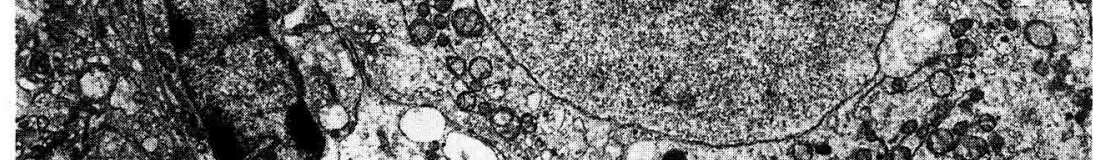

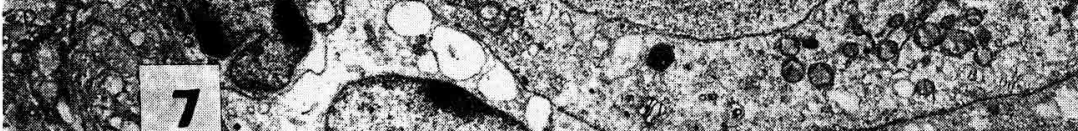

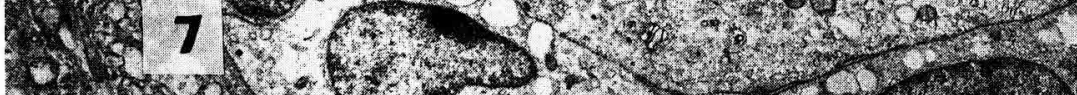

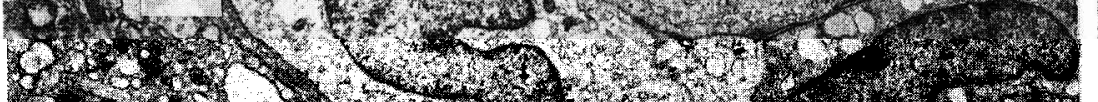

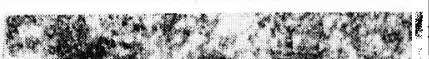

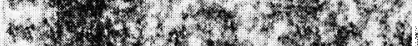

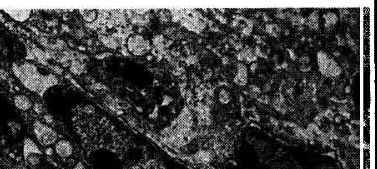
$3^{2}+x^{2}+x^{2}+23$
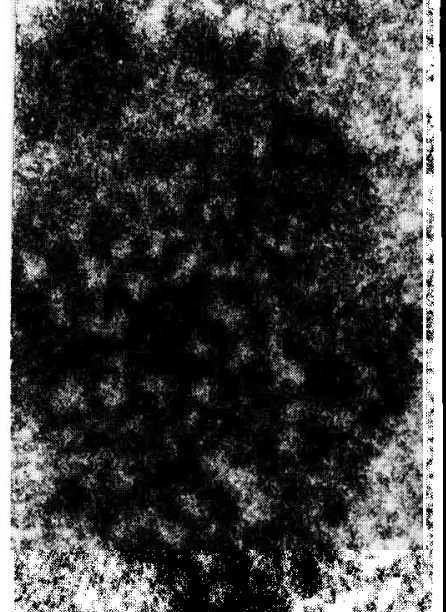


\section{DISCUSSION}

Meiotic prophase in mammalian oocytes has been suggested to proceed through diplotene to a relatively long stationary stage, the dictyate, in which the nuclear chromatin is highly decondensed (Franchi et al, 1962; Baker, 1971; Baker and Franchi, 1972). In the present study, aggregated oocyte nuclear chromatin was observed only in 1 population of the UF follicles. However, such nuclear configuration reminiscent of diplotene oocyte was observed by Baker and Franchi (1967) in near-term and early postnatal calves. The second oocyte population of the UF follicles contained nuclear configuration indicative of the dictyate stage: the nuclear chromatin highly decondensed and the nucleoli apparently differentiated into fibrillar, fibrillogranular and granular components assuming a reticulated form (Franchi et al, 1962; Baker, 1971; Baker and Franchi, 1972).

The present findings are in contrast with previous observations of Lintern-Moore and Moore (1979a, b) and Arendsen de Wolff-Exalto and Groen-Klevant (1980) who have suggested a decisive role for the surrounding cuboidal follicle cells in oocyte growth initiation. Most of the oocytes of the UC follicles did not grow significantly although they were surrounded by a complete layer of cuboidal follicle cells. It is noteworthy, however, that the endoplasmic reticulum of the first oocyte population of the UC follicles appeared at the ultrastructural level as less-developed small vesicular elements. Furthermore, oocytes containing spare endoplasmic reticulum have been reported to exist in primates during the early stages of folliculogenesis (Baker and Franchi, 1972). Therefore, it was likely that the oocytes in which the development was not possible of one or several subcellular organelles were unable to answer the growth-inducing stimuli of the surrounding cuboidal follicle cells.

On the other hand, if this was true, the question of why the well-developed subcellular organelles contained within the second oocyte populations of the UF and the UFC follicles enabled these oocytes to initiate growth significantly would arise. However, this could be explained by the assumption that the surrounding follicle cells of the UF or the UFC follicles which have been proposed to generate oocyte growthinducing stimuli (Buccione et al, 1987; Colonna et al, 1989) were not yet competent in this stage of follicle development. This capacity might be acquired in the course of follicle cell transition from flattened to cuboidal shape which has been suggested to be under the influence of gonadotropins (Arendsen de Wolff-Exalto, 1982). Therefore, it was tempting to speculate that the morphological changes of the oocyte subcellular organelles as well as the concomi-

Fig 6. An electron micrograph of a unilaminar flatto-cuboidal ovarian follicle (UFC) with an oocyte of population $1(n=5)$. The oocyte nuclear chromatin decondenses uniformly. The nucleolus is prominent and reticulated. In the cytoplasm, the endoplasmic reticulum (ver) appears as small vesicular elements among the numerous well-differentiated mitochondria (m) (x 1500$)$.

Fig 7. An electron micrograph of a unilaminar flatto-cuboidal ovarian follicle (UFC) with an oocyte of population $2(n=7)$. The oocyte nuclear chromatin decondenses uniformly in the nuclear area. The nucleolus (inset, $\times 8000$ ) differentiates into fibrillar, fibrillo-granular and granular components assuming a reticulated form. The endoplasmic reticulum (fer) appear as flattened cisternae associated with numerous well-differentiated mitochondria $(m)(x 1500)$. 
Flg 8. An electron micrograph of a unilaminar cuboidal ovarian follicle (UC) with an oocyte of population $1(n=4)$. The oocyte nuclear chromatin, like that of the UFC follicles, decondenses uniformly. The nucleolus (inset, $\times 10$ 000) differentiates into fibrillar, fibrillo-granular and granular components assuming a reticulated form. The cytoplasm contains an abundance of mitochondria $(m)$ but the endoplasmic reticulum (ver) was scarcely recognized as small vesicular elements $(\times 1500)$.

Fig 9. An electron micrograph of a "giant oocyte" $(n=2)$. The nuclear envelope invaginates deeply (large arrow) and the nuclear chromatin aggregates into moderately electrondense small patches (arrowhead). The nucleolus (inset, $\times 12000$ ) is fibrillo-granular in texture within which an incipient electron-dense fibrillar component is seen (small arrow). Small vesicular elements (ver) as well as flattened cisternae (fer) of the endoplasmic reticulum associated with mitochondria $(\mathrm{m})$ are found in the cytoplasm (x 1500).

tant complete transition of the follicle cells from flattened to cuboidal shape, which might imply the generation of putative oocyte growth-inducing stimuli, were complementary events essential for the initiation of oocyte growth. Thus, initiation of oocyte growth was expected only in follicles in which the presence of these 2 complementary events was coincidental. This was probably manifested in oocytes of the Feulgen negative class as well as the very intensive labelling group of the UC follicles in which the diameter increased significantly.

The non-crucial role of the surrounding follicle cells in initiating oocyte growth (Eshkol and Lunenfeld, 1972) was further unequivocally demonstrated in the present study by the observation of the "giant oocytes". These findings might suggest that events initiated in the mouse itself were more decisive. However, the "giant oocytes" could not survive when they continued to grow without sufficient nutritional support from the starved surrounding follicle cells. This could be predicted, however, from the nuclear envelope invagination (Staňková and Čech, 1983; Stanková et al, 1985) and probably from the aggregation of the nuclear chromatin into small patches.

\section{ACKNOWLEDGMENTS}

The authors are indebted to $\mathrm{J}$ Fulka for constructive discussions, JE Fléchon for translation of the French summary, E Grudová, J Schwarzová, V Pech and $F$ Zavrel for their technical assistance. Thanks to $J$ Jenkins for editing the manuscript.

\section{REFERENCES}

Arendsen de Wolff-Exalto $E$ (1982) Influence of gonadotropins on early follicle cells development and early oocyte growth in the immature rat. J Reprod Fertil 66, 537-542

Arendsen de Wolff-Exalto $E$, Groen-Klevant AC (1980) Oocyte growth in the immature rat. J Reprod Fertil 59, 187-192

Baker TG (1971) Electron microscopy of the primary and secondary oocyte. Adv Biosci 6, 727

Baker TG, Franchi LL (1967) The fine structure of chromosomes in bovine primordial oocytes. J Reprod Fertil 14, 511-513

Baker TG, Franchi LL (1972) The fine structure of oogonia and oocyte in the Rhesus monkey (Macaca mulatta). Z Zellforsch 126, 53-74

Buccione R, Cecconi S, Tatone C, Mangia F, Colonna R (1987) Follicle cell regulation of mammalian oocyte growth. $J$ Exp Zool 242, 351-354 
Cahill LP, Mauléon P (1981) A study of the population of primordial and small follicles in the sheep. J Reprod Fertil 61, 201-206

Colonna R, Cecconi S, Tatone C, Mangia F, Buccione R (1989) Somatic cell-oocyte interactions in mouse oogenesis: stage-specific regulation of mouse protein phosphorylation by granulosa cells. Dov Biol 133, 305-308

Crozet N, Motlík J, Szöllosi D (1981) Nucleolar fine structure and RNA synthesis in porcine oocytes during the early stages of antrum formation. Biol Cell 41, 35-42

Dostál J, Matoušek J (1973) Isolation and some chemical properties of aspermatogenic substance from bull seminal vesicle fluid. J $R e$ prod Fertil 33, 263-274

Eshkol A, Lunenfeld B (1972) Gonadotropic regulation of ovarian development in mice during infancy. In: Gonadotropins (Saxena BB, Beling CC, Gandy HM, eds), NY, 335-346

Franchi LL, Mandl AM, Zukerman S (1962) The development of the ovary and the process of oogenesis. In: The Ovary (Zukerman SS, ed) Academic Press, Vol 1, 1-88

Gougeon A, Chainy GBN (1987) Morphometric studies of small follicle in ovaries of women at different ages. $J$ Reprod Fertil 81, 433-442

Gurr A (1962) Staining Animal Tissues. Practical and Theoretical. Leonard Hill Ltd, London

Lillie RD (1965) Histopathologic Technic and Practical Histochemistry. McGraw-Hill Book Company, NY
Lintern-Moores, Moore GPM (1979a) The initiation of oocyte growth in the mouse ovary. Ann Biol Anim Biochim Biophys 19, 13991407

Lintern-Moore S, Moore GPM (1979b) The initiation of follicle and oocyte growth in the mouse ovary. Biol Reprod 20, 773-778

Matton P, Adelakoun V, Couture Y, Dufour JJ (1981) Growth and replacement of the bovine ovarian follicles during the estrous cycles. $J$ Anim Sci 52, 813-820

Maurasse C, Matton P, Dufour JJ (1985) Ovarian follicular populations at two stages of an estrous cycle in heifers given high energy diets. J Anim Sci 61, 1194-1200

Rajakoski E (1960) The ovarian follicular system in sexually mature heifers with special reference to seasonal, cyclical and left-right variations. Acta Endocrinol (suppl 52) / L11 /, 96

Savio JD, Keenan MP, Boland MP, Roche JF (1988) Pattern of growth of dominant follicles during the oestrous cycle of heifers. J Reprod Fertil 83, 663-671

Staňková, Čech S (1983) Ultrastructural changes during atresia of human ovarian follicles. 1. Primordial follicles. $Z$ Mikroscop Anat Forsch (Leipzig) 97, 915-928

Staňková J, Čech S, Sedláčková M, Kristek F (1985) A morphometric comparative study of healthy and atretic human primordial follicles. $Z$ Mikroskop Anat Forsch (Leipzig) 99, 510518 